\title{
Entre a Concepção e o Resultado: modelos de gestão dos planos PluRianuais como INSTRUMENTOS DE GESTÃO DA AÇÃO GOVERNAMENTAL ${ }^{1}$
}

Sheila Cristina Tolentino Barbosa²

\section{INTRODUÇÃO}

Os planos plurianuais (PPAs), enquanto planos estratégicos governamentais, representaram avanço na organização da ação estatal no nível federal, tanto pelo aspecto democrático de sua construção quanto pela articulação dessa ação com componentes orçamentários e financeiros ainda que com limitações. Contudo, sua função na qualidade de instrumento de gestão da ação governamental para o alcance de resultados merece um exame mais detalhado. Este artigo tem por objetivo descrever e discutir os modelos de gestão da implementação dos PPAs, desde 2000, a partir dos arranjos de atores institucionais ${ }^{3}$ envolvidos, explorando limites e possibilidades ao longo de suas ediçóes. A metodologia aplicada envolve análise qualitativa via pesquisa documental, de modo a examinar, em perspectiva comparada, as mudanças nos modelos de gestáo adotados e suas implicaçóes sobre a gestão da ação governamental.

A promoção do bem-estar da sociedade, finalidade da ação governamental, requer direcionamento, sendo os planejamentos estratégico, tático e operacional o ponto de partida para conceber, priorizar e orientar a ação estatal no sentido de obter os resultados desejados. Entre a concepção e os resultados, no entanto, há o agir, o pôr em prática, ou seja, o esforço de formulação não é suficiente para garantia dos resultados desejados. Dessa forma, o processo de gestão dos planos estratégicos passa a ser igualmente relevante para o sucesso na entrega de resultados, o que torna indispensável a compreensão e o domínio desse processo em todas as suas etapas. Nesse sentido, são discutidas a seguir as institucionalidades que determinam a gestão dos PPAs no âmbito federal nos anos recentes, de maneira a fornecer uma visáo geral de seus elementos condicionantes, limites e possibilidades.

Planejamentos estratégicos, em geral, visam um certo domínio da realidade, de modo a obter os resultados pretendidos. Na perspectiva dos que governam, trata-se de esforço para controlar variáveis que podem interferir nos resultados de políticas públicas, sejam elas relativas a fatores ambientais ou ao comportamento de atores na arena dessas políticas. Desse modo, o plano serve de suporte à ação do dirigente, conforme destaca Matus (2007).

Segundo Matus (2007), a dinâmica do processo de planificação é composta de quatro momentos, a saber: i) momento explicativo; ii) momento normativo; iii) momento estratégico; e iv) momento tático-operacional. A despeito de ser uma fase delineada por decisóes das fases anteriores, a fase tático-operacional (o fazer) é tão relevante quanto os momentos que constituem as decisóes anteriores ao fazer.

1. DOI: http://dx.doi.org/10.38116/bapi27art3

2. Especialista em políticas públicas e gestão governamental na Diretoria de Estudos e Políticas do Estado, das Instituições e da Democracia (Diest) do Ipea; e professora adjunta do Departamento de Gestão Pública da Universidade de Brasília.

3. Destaca-se o alinhamento da escolha da abordagem institucional ao objetivo deste artigo por meio da seguinte consideração de Hall e Taylor (2003, p. 194): as diferentes vertentes do institucionalismo "buscam elucidar o papel desempenhado pelas instituições na determinação de resultados sociais e políticos". 
Essencial é dispor de um sistema de direção estratégica, que chame atenção sobre as importâncias e os processos, de modo técnico-político, e sobre as propostas centrais de decisão. Mas nada disso é possível se o jogo institucional for de baixa responsabilidade, não existir gerência criativa por operaçóes e o dirigente não prestar contas nem souber exigi-las de seus executivos (Matus, 2007, p. 142).

Isso significa dizer que os modelos de gestão institucionalizados a cada PPA são elementos diferenciais para o sucesso ou enfraquecimento dos planos, uma vez que condicionam a ação governamental. Contudo, vale lembrar que o contexto da ação pública é permeado pela disputa de poder no cenário político. A própria estrutura administrativa do Estado é objeto da ocupação partidária na busca por controle sobre decisóes de alocação de recursos, conforme descrito por Silva e Barbosa (2019). Dessa forma, os resultados da ação governamental são decorrentes de um somatório de fatores que caracterizam sua multicausalidade. De todo modo, ainda que os resultados estejam sob a influência de múltiplas variáveis, o exame detalhado com recortes de variáveis constitui empreendimento útil para compreensão dos elementos que configuram a complexidade e condicionam a ação governamental.

O texto está organizado da seguinte forma: além desta introdução, a segunda seção fornece uma visão geral das principais características dos modelos de gestão dos PPAs; na terceira seção, são exploradas as institucionalidades que definem os modelos de gestão e os atores institucionais a cada edição do PPA; por fim, a quarta seção traz as considerações finais.

\section{MODELOS DE GESTÃO DOS PPAS AO LONGO DO TEMPO}

Ao observar como se desenvolve o processo de gestão dos planos estratégicos do governo federal nos anos recentes, destaca-se que, como resultado de um processo de evoluçáo e amadurecimento na retomada do planejamento governamental no período pós-redemocratização, o primeiro esforço de institucionalização de um modelo de gerenciamento dos PPAs é observado no Decreto nํ 2.829, de 29 de outubro de $1998,{ }^{4}$ em que são prescritos de modo muito sucinto a definição de unidade responsável pelo gerenciamento, o controle de prazos e custos e um sistema informatizado de apoio ao gerenciamento. ${ }^{5}$ Esta prescrição foi direcionada ao PPA 2000-2003, sendo que os PPAs anteriores, 1991-1995 e 1996-1999, estiveram concentrados no objetivo de estabelecer ordem e coerência entre a ação e o gasto governamental, tratando-se, à época, de iniciar a tarefa de conceber os planos e atrelá-los a um plano orçamentário.

As novas orientações propostas a partir do PPA 2000-2003 conferiram especial ênfase à gestão e à avaliação e ordenavam que cada programa fosse dotado do modelo de gerenciamento proposto. As alteraçóes da programação orçamentária e do fluxo financeiro de cada programa passaram a ser condicionadas à informação prévia pelos respectivos gerentes, por meio de sistema informatizado, com indicação do grau de alcance das metas fixadas. Desta forma, o processo de gestão passaria a ser orientado pela avaliação de eficiência e eficácia, sendo as metas físicas o parâmetro próprio da

4. Embora o PPA 1996-1999 tenha sido a primeira experiência (piloto) de estruturação do plano na linha de orçamento por resultados, não se observa menção formal específica quanto a um modelo de gestão para o referido PPA.

5. De 1987 a 2004, Sistema Integrado de Dados Orçamentários (SIDOR), posteriormente, Sistema de Informações Gerenciais e de Planejamento (SIGPLAN). Em 7 de maio de 2009, a Secretaria de Orçamento Federal (SOF), em conjunto com a Secretaria de Planejamento e Investimento Estratégicos (SPI) - depois Secretaria de Planejamento e Assuntos Econômicos (SEPLAN) -, lançou o Sistema Integrado de Planejamento e Orçamento (SIOP) para cadastro de programas e ações. De 2009 em diante, o SIDOR e o SIGPLAN foram substituídos pelo SIOP (Araujo da Silva, 2019). 
lógica de uma administração pública orientada a resultados (Garcia, 2015; Couto e Cardoso Junior, 2020). A gestão estratégica do PPA torna-se, assim, mais complexa.

Ainda como resultado da proposta concebida e instituída em 1998, o PPA 2000-2003 inovou também ao prescrever um modelo de gestão que incluía a gestão de prioridades de governo, sendo delineado pela proposição: i) do papel de gerente de programa; ii) da definição de unidade responsável; iii) da gestão de restriçôes e avaliação do desempenho físico-financeiro como forma de monitorar e avaliar resultados; e iv) da avaliação do grau de satisfaçáo da sociedade em relação a produtos e serviços oferecidos pelo governo federal. Tudo isso demandava o monitoramento com controle de prazos e custos por meio de sistema de informaçóes gerenciais, também previsto como proposição (Garcia, 2015).

Essa noção de gestão de prioridades se consolida a partir do PPA 2004-2007 com a definição do termo programa prioritário em glossário, com continuidade de seu uso nos demais PPAs ${ }^{6}$ até o momento atual. Contudo, o lançamento do Programa de Aceleração do Crescimento (PAC) em 2007 desloca, no PPA subsequente, a função de gestão de prioridades para a Casa Civil, o que leva a um esvaziamento de papeis dos atores envolvidos no modelo de gestáo do PPA 2008-2011, em favor de uma maior concentração de esforços na gestão de programas componentes do PAC (Couto e Cardoso Junior, 2020).

Na busca por integrar os elementos da complexidade, neste caso materializada pelas transformaçóes na avaliação e gestão de prioridades dos planos mencionados, faz-se necessário lidar com as racionalidades política, administrativa e gerencial, dado que a gestão estratégica no setor público, orientada a resultados, se desenvolve em cenário de diversidade de stakeholders e determinada por três tipos de poder: o poder de escolha, o poder da lei e o poder de modos e meios (Mazouz e Rousseau, 2016).

Na mesma direção, Dagnino, Cavalcanti e Costa (2016) informam que a efetividade da gestão estratégica pública se dá por três sistemas: o de constituição da agenda, o chamado menu de decisóes; o de cobrança e prestação de contas, que torna efetiva a responsabilidade sobre compromissos de entregas - elemento destacado por Matus (2007) como essencial à efetividade dos planos, conforme ressaltado anteriormente - e que trata de constituir processos de trabalho com base na responsabilidade; e, por fim, o sistema de gestão operacional, em que a ação está sujeita a diretrizes, mas com espaço para a criatividade, a iniciativa e a inovação. Estão também inclusos como mecanismos de suporte para a efetividade os sistemas como os de gestão de crises e de comunicação governamental. Os autores destacam ser fundamental identificar e disponibilizar os meios indispensáveis para a ação e os diversos recursos necessários, tais como poder político, conhecimento, capacidades organizativas, equipamentos e tecnologia e, também, mas nem sempre, recursos econômico-financeiros.

Com tais referências sobre os elementos essenciais ao processo de gestão estratégica em mente, a análise aqui concentra-se na discussão dos determinantes institucionais de implementação do plano, mais especificamente de seu modelo de gestão. Assim, a variável em destaque na análise trata dos atores institucionais presentes nos modelos de gestão dos planos, levando em consideração: i) a estrutura administrativa de coordenação e de gerenciamento estratégico do PPA delineada por essas institucionalidades; ii) as condições de adaptação dos planos e espaços para criatividade e inovação; e iii) a atividade de monitoramento que informa a tomada de decisão nesse processo de gerenciamento.

6. Foi observada a publicação de decretos com indicação de programas prioritários ou ações prioritárias, a exemplo do Decreto n- 5.248, de 20 de outubro de 2004. 


\section{DETERMINANTES INSTITUCIONAIS DA GESTÃO DOS PPAS DO GOVERNO FEDERAL}

Em razão das sucessivas leis e decretos que estabeleceram os PPAs e seus modelos de gestão, ao longo do tempo o modelo de gestáo do PPA torna-se uma complexa teia de atores com sobreposiçáo de funçóes, em especial as de avaliação e monitoramento de aspectos do plano. Nestes modelos, os principais atores são: a Casa Civil, o Ministério do Planejamento, Orçamento e Gestão, as Câmaras do Conselho de Governo, o Comitê Gestor, a Câmara de Qualidade dos Programas e Açóes do Plano Plurianual, a Comissão de Monitoramento e Avaliação (CMA), os órgão executores (incluindo secretários, gerentes e coordenadores executivos e gerentes e coordenadores de açóes) e as Unidades de Monitoramento e Avaliação (figura 1).

FIGURA 1

Atores institucionais da estrutura de gestão do PPA

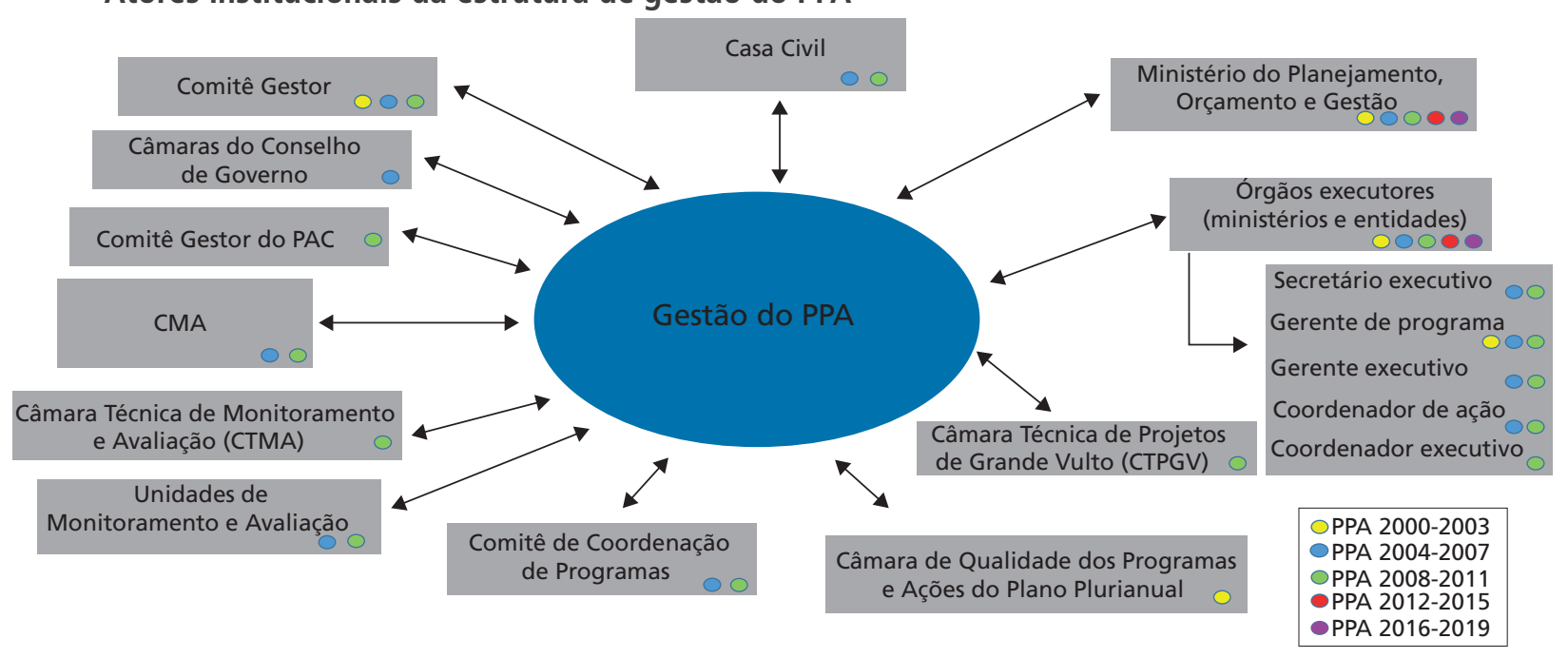

Elaboração da autora.

Obs.: As informações fornecidas baseiam-se em pesquisa documental em sites oficiais do governo.

Conforme ilustrado na figura 1 , a complexidade do modelo de gestão do PPA é caracterizada por um processo incremental, uma vez que novos conjuntos de atores e regras foram continuamente sendo agregados a esse processo. Como será esclarecido mais à frente, contudo, houve também períodos de redução dos atores institucionais.

A partir das definiçốes contidas no Decreto no 2.829, de 1998, que trata de modelo de gerenciamento para o PPA 2000-2003, observa-se um esforço no sentido de definir atores e estruturas do gerenciamento. Destaca-se que os gerentes de programas são mencionados nesse decreto, já os coordenadores de açôes são mencionados a partir do Decreto no 5.233, de 2004 (quadro 1). É a partir deste último que ambos passam a vincular-se diretamente às unidades administrativas responsáveis pelos programas e açóes, em uma estrutura administrativa paralela à estrutura organizacional delineada por ministérios e suas unidades (Garcia, 2015). Ao mesmo tempo, foi criado o então Sistema de Monitoramento e Avaliação (SMA), coordenado pela CMA, e composto por Unidades de Monitoramento e Avaliação. 
QUADRO 1

Trajetória dos atores institucionais dos modelos de gestão dos PPAs do governo federal

\begin{tabular}{|c|c|c|c|c|c|c|}
\hline \multirow[b]{2}{*}{ Atores institucionais } & \multicolumn{6}{|c|}{ Especificação do decreto e PPA de referência } \\
\hline & \begin{tabular}{|c|}
$n-2.829 / 1998$ \\
$2000-2003$ \\
\end{tabular} & \begin{tabular}{|c|}
$n-4.052 / 2001$ \\
$2000-2003$ \\
\end{tabular} & $\begin{array}{c}n=5.233 / 2004 \\
2004-2007 \\
\end{array}$ & $\begin{array}{c}n=6.601 / 2008 \\
2008-2011 \\
\end{array}$ & $\begin{array}{c}n=7.866 / 2012 \\
2012-2015 \\
\end{array}$ & \begin{tabular}{|c|}
$n=8.759 / 2016$ \\
$2016-2019$ \\
\end{tabular} \\
\hline Casa Civil & - & - & $x$ & $x$ & - & - \\
\hline Ministério do Planejamento, Orçamento e Gestão & $x$ & $x$ & $X$ & $X$ & $X$ & $x$ \\
\hline Câmaras do Conselho de Governo & - & - & $X$ & - & - & - \\
\hline Câmara de Qualidade dos Programas e Ações do Plano Plurianual & - & $x$ & - & - & - & - \\
\hline Comitê Gestor & $x$ & - & $x$ & $x$ & - & - \\
\hline Comitê Gestor do PAC & - & - & - & $x$ & - & - \\
\hline Comitê de Coordenação de Programas & - & - & $x$ & $X$ & - & - \\
\hline CTMA & - & - & - & $x$ & - & - \\
\hline CTPGV & - & - & - & $x$ & - & - \\
\hline CMA & - & - & $x$ & $x$ & - & - \\
\hline Unidade de Monitoramento e Avaliação & - & - & $x$ & $x$ & - & - \\
\hline Órgãos executores & $x$ & $x$ & $x$ & $x$ & $X^{2}$ & $x$ \\
\hline Secretário executivo & - & - & $x$ & $x$ & - & - \\
\hline Gerente de programa & $x$ & - & $X$ & $x$ & - & - \\
\hline Gerente executivo & - & - & $x$ & $x$ & - & - \\
\hline Coordenador de ação & - & - & $x$ & $x$ & - & - \\
\hline Coordenador executivo & - & - & - & $x$ & - & - \\
\hline
\end{tabular}

Elaboração da autora.

Notas: ${ }^{1}$ Documento complementar ao Decreto ㄲo 2.829/1998.

2 Definidos como órgãos responsáveis por objetivos.

Obs.: As informaç̃̃es fornecidas baseiam-se em pesquisa documental em sites oficiais do governo.

Em continuidade aos primeiros esforços de definiçôes da gestáo do PPA 2000-2003, o decreto que estabeleceu normas para a gestáo do PPA 2004-2007 foi direcionado a constituir processos de trabalho com base na responsabilidade, e inseriu adicionalmente os papéis de gerentes executivos de programas e coordenadores executivos de ação, na direção do que Matus (2007) destacou como essencial à efetividade dos planos. Contudo, a complexidade resultante foi questionada quanto aos seus efeitos. É nos PPAs 2004-2007 e 2008-2011 que se observa listada maior variedade de atores institucionais, conforme respectivos decretos de gestáo do plano (quadro 1).

A despeito dos esforços de aperfeiçoamento da gestáo do PPA, ou talvez mesmo em razáo da complexidade delineada pelas mudanças implementadas até 2007 e ampliadas no PPA 2008-2011, as transformaçóes resultantes aparentemente não promoveram a visão de um instrumento realmente útil ao processo de entrega de bens e serviços à sociedade, ao contrário, conforme destacam Couto e Cardoso Junior (2020, p. 22), "o PPA pouco agregava aos processos de planejamento dos ministérios setoriais, sendo visto apenas como instrumento burocrático e de prestaçáo de contas". Na mesma linha de pensamento, Cavalcante (2012) destaca resultados de implementação abaixo do esperado para os modelos de gestão dos PPAs de 2000 a 2007.

Para além disso, houve mençôes quanto à divergência significativa entre os gestores no que se refere à forma como se estrutura a gestáo do PPA. Mais especificamente, houve divergência sobre 
uma suposta ou necessária arquitetura de governança sobre as etapas, as funçóes, as instituições, os processos e os instrumentos desse complexo circuito de atribuições governamentais que envolve, entre outras, as funçôes de planejamento, orçamentação, gestão, avaliação e controle da coisa pública (Cardoso Junior, 2011, p. 452).

Isso ensejou uma inflexão na proposta do modelo de gestão para o período 2012-2015, com uma simplificação drástica quanto aos tipos de atores institucionais envolvidos.

Essa noção de burocratização dos processos de monitoramento e avaliação se maximiza no PPA 2008-2011, não só por este reproduzir a estrutura do período 2004-2007 mas também porque foram instituídas duas novas câmaras técnicas, uma de monitoramento e avaliação e outra de projetos de grande vulto, ambas em apoio à CMA. Há visivelmente um maior foco na prestação de contas do que de fato em um espaço de gerência criativa, como propóe (Matus, 2007). Neste sentido, parece haver um desequilíbrio, sugerindo a razão da percepção de um modelo de gestão engessado, caracterizado como um processo burocrático de prestação de contas, ainda que seja um modelo concebido como orientado a resultados, como informa Cavalcante (2012).

Possivelmente em reação a essas percepções de engessamento, o Decreto nํㅜ 7.866/2012, ao se referir à gestão do PPA, no lugar de estabelecer um modelo de gestáo para o plano, a exemplo dos três planos anteriores, limita-se a informar referências para o processo de gestão, entre elas:

- o aproveitamento das estruturas de monitoramento e avaliaçáo existentes e a responsabilização compartilhada para realizaçáo dos objetivos e alcance das metas de cada programa temático;

- a consideração das especificidades de implementação de cada política pública e da complementaridade entre elas;

- a articulação e cooperação interinstitucional para fins de produção e organização das informações relativas à gestão;

- o fortalecimento do diálogo com os entes federados;

- a participação social na gestão do PPA; e

- o aprimoramento do controle público sobre o Estado.

Observado dessa forma, aparentemente, no PPA 2012-2015, houve um desmonte da estrutura de gestão anterior, sob a pretensão de soltar amarras em favor de uma maior flexibilidade de gestão, adequada às particularidades de cada programa. Ademais, sequer houve a publicação do manual de gestão do respectivo PPA, como já era a prática. Adicionalmente, os executores passaram a ser responsáveis por objetivos, sendo que cada programa era composto por vários objetivos.

Naquele momento, indicadores passaram a ser vinculados a programas temáticos, diferentemente das metas. De acordo com Couto e Cardoso Junior (2020, p. 23), "os indicadores prestavam-se a uma função de monitoramento do contexto da situação na qual o tema se inseria, e o plano tornou-se instrumento de comunicação e transparência”, mas com perda de relevância no âmbito do planejamento, dada a ausência de um modelo de gestão claramente estruturado.

O PPA 2016-2019, por sua vez, ao seguir o modelo de gestão do PPA 2012-2015, se afasta de vez dos modelos anteriores, visto que o decreto nem mesmo menciona o aproveitamento de estruturas de monitoramento e avaliação preexistentes. No seu respectivo decreto, há apenas a menção 
à atuação conjunta do Ministério do Planejamento, Orçamento e Gestão e os órgãos executores na coordenação e monitoramento do PPA.

Nesse sentido, e tomando como referência a proposição de Matus (2007) sobre sistema de direção estratégica, que chame atenção tanto para as importâncias e os processos no que se refere à ação governamental, de modo técnico-político, quanto para as propostas centrais de decisão, o sistema de direção estratégica do PPA 2016-2019 parece se afastar de tal centralização observada sobretudo no PPA 2008-2011 com a gestão do PAC - isto aparentemente em favor de um arranjo que oferece mais flexibilidade do ponto de vista setorial.

\section{CONSIDERAÇÕES FINAIS}

A trajetória de mudanças no modelo de gestão dos PPAs do governo federal é marcada pelo incrementalismo durante a maior parte do período analisado, e momentos de inflexóes são percebidos nas transições para o PPA 2000-2003 e o PPA 2012-2015. Tais inflexões são orientadas a, no primeiro caso, um modelo de gestão de contornos bastante definidos, com ênfase sobre o registro de informaçóes, a definição de responsabilidades e a prestação de contas, e, no segundo caso, a uma maior flexibilização em certa medida com vistas à iniciativa, criatividade e inovação no âmbito setorial.

Nas características dessa trajetória é ainda perceptível tanto o crescente ganho de relevância dos PPAs quanto seu esvaziamento à medida que o número de atores institucionais envolvidos em sua gestão experimenta constante crescimento de 2000 a 2011 e drástica redução a partir de 2012, paralelamente à centralização e concentração de esforços na gestão do PAC. Tal cenário aparentemente sinaliza retrocesso, com a perda de espaço dos planos estratégicos, que perpassam distintos governos, para o modelo de plano constituído enquanto plataforma de governo. Ocorre o prenúncio da passagem da orientação por projeto de estado para a orientação por projeto de governo.

No que se refere a capacidades organizativas, alguns desafios à sua efetividade se fazem notar a partir da orientação dessas inflexôes com implicações sobre a gestão da ação governamental. Se, de um lado, os modelos de gestão que mais se aproximam daqueles com estruturas administrativas paralelas e dedicadas, de contornos mais definidos e complexidade decorrente da maior variedade de atores impóem dificuldades de adaptabilidade à gestão governamental, de outro lado, os modelos de gestão mais descentralizados, com mais autonomia das unidades executoras e delineados pelas estruturas administrativas setoriais apresentam desafios à coesão das ações de monitoramento e avaliação e ao domínio de resultados.

Como apontamento para uma agenda de pesquisa futura, propóe-se o exame dos modelos de gestão do PPA em associaçáo à análise do alcance dos resultados em cada uma de suas edições.

\section{REFERÊNCIAS}

ARAUJO DA SILVA, Felipe Cesar. SIOP: Sistema Integrado de Planejamento e Orçamento. Belém: ENAP, 2019. Disponível em: <https://bit.ly/3aRTA0m>.

CARDOSO JUNIOR, José Celso (Org.). A reinvenção do planejamento governamental no Brasil. Brasília: Ipea, 2011. (Diálogos para o Desenvolvimento, v. 4). 
CAVALCANTE, Pedro Luiz Costa. Avaliação dos programas do PPA: estudo de caso da implantação do orçamento por desempenho. Gestáo e Planejamento, v. 13, n. 2, 2012.

COUTO, Leandro Freitas; CARDOSO JUNIOR, José Celso. A função dos planos plurianuais no direcionamento dos orçamentos anuais: avaliação da trajetória dos PPAs no cumprimento da sua missão constitucional e o lugar do PPA 2020-2023. Brasília: Ipea, 2020. (Texto para Discussão, n. 2549).

DAGNINO, Renato; CAVALCANTI, Paula Arcoverde; COSTA, Greiner. Gestáo estratégica pública. São Paulo: Editora Fundação Perseu Abramo, 2016.

GARCIA, Ronaldo Coutinho. A reorganização do processo de planejamento do governo federal: o PPA 2000-2003. In: CARDOSO JUNIOR, José Celso; CUNHA, Alexandre dos Santos (Org.). Planejamento e avaliação de políticas públicas. Brasília: Ipea, 2015.

HALL, Peter A.; TAYLOR, Rosemary C. R. As três versões do neo-institucionalismo. Lua Nova: Revista de Cultura e Política, n. 58, p. 193-223, 2003.

MATUS, Carlos. O plano como aposta. In: . Planejamento e orçamento governamental. Brasília: ENAP, 2007. v. 1.

MAZOUZ, Bachir; ROUSSEAU, Anne. Strategic management in public administrations: a results-based approach to strategic public management. International Review of Administrative Sciences, v. 82, n. 3, p. 411-417, 2016.

PAULO, Luiz Fernando Arantes. O PPA como instrumento de planejamento e gestão estratégica. Revista do Serviço Público, v. 61, n. 2, p. 171-187, 2010.

SILVA, Noëlle da; BARBOSA, Sheila Cristina Tolentino. Trajetória da ocupaçáo partidária nos setores temáticos da estrutura do Poder Executivo (1986-2016). Rio de Janeiro: Ipea, 2019. (Texto para Discussáo, n. 2453). 